\title{
FITOTECNIA
}

\section{QUALIDADE DE FRUTOS DE TOMATEIRO COM E SEM ENXERTIA ( ${ }^{1}$ )}

\author{
SUANE COUTINHO CARDOSO $\left({ }^{2}\right)$; ANA CRISTINA FERMINO SOARES $\left({ }^{3}\right)$; \\ ALEXSANDRO DOS SANTOS BRITO $\left({ }^{4}\right)$; LEA ARAÚJO DE CARVALHO $\left({ }^{3}\right)$; CELMA \\ CARDOSO PEIXOTO $\left({ }^{4}\right)$; MÁRCIO EDUARDO CANTO PEREIRA $\left({ }^{5}\right)$; ELAINE GOES $\left({ }^{5}\right)$
}

\begin{abstract}
RESUMO
Este trabalho teve como objetivo a caracterização física e físico-química de frutos de tomateiro oriundos de plantas enxertadas em comparação com plantas pés-franco. A enxertia foi realizada utilizandose o método de fenda cheia tendo o híbrido Hawaii 7996 como porta-enxerto, resistente à murcha bacteriana, e as cultivares Santa Clara e Santa Cruz Kada e o híbrido Débora Plus como enxerto. O delineamento experimental foi em blocos ao acaso, com seis tratamentos (três enxertados e três pésfranco) e cinco repetições de campo. Foram avaliadas as seguintes características: massa média dos frutos, diâmetros transversal e longitudinal, sólidos solúveis totais (SST), pH, acidez total titulável (ATT) e a relação SST / ATT. A enxertia não alterou as características acima descritas para os frutos de tomate, quando comparados aos frutos oriundos de plantas pés-franco, com exceção do pH para as duas cultivares utilizadas. O híbrido 'Hawaii 7996' pode ser utilizado como porta-enxerto com as cultivares comerciais Santa Clara e Santa Cruz Kada e o híbrido Débora Plus, sem prejuízo para a qualidade do fruto do tomateiro.
\end{abstract}

Palavras-chave: Lycopersicon esculentum, enxertia, Hawaii 7996, qualidade do fruto.

\section{ABSTRACT \\ QUALITY CHARACTERISTICS OF TOMATO FRUITS FROM GRAFTED PLANTS}

This research was conducted with the objective of characterizing the physical and physical-chemical characteristics of tomato fruits from grafted plants as compared to those from own rooted seedlings. Cultivars Santa Clara, Santa Cruz Kada, and the hybrid Débora Plus were cleft grafted on to hybrid Hawaii 7996, resistant to bacterial wilting, as the rootstock. The experimental design was the completely randomized blocks, with six treatments (three grafted and three ungrafted), with five replications in the field. It were evaluated fruit weight, length and width, total soluble solids (TSS), $\mathrm{pH}$, titratable total acidity (TTA), and the ratio TSS/TTA. Grafting did not affect the above characteristics, except for $\mathrm{pH}$ of the two cultivars. Thus, the hybrid 'Hawaii 7996' can be used as commercial rootstock for cultivars 'Santa Clara'; 'Santa Cruz Kada' and the 'Débora Plus' hybrid, without affecting fruit quality.

Key words: Lycopersicon esculentum, Hawaii 7996, rootstock, bacterial wilt.

(1) Recebido para publicação em 21 de setembro de 2004 e aceito em 20 de abril de 2006.

$\left({ }^{2}\right)$ Mestranda, Curso de Pós-graduação em Ciências Agrárias, Escola de Agronomia da UFBA, Cruz das Almas (BA). Bolsista CAPES. E-mail: suanec@bol.com.br

$\left({ }^{3}\right)$ Departamento de Fitotecnia, Escola de Agronomia da UFBA, 44380-000 Cruz das Almas (BA). E-mail: acsoares@ufba.br. Autor correspondente.

(4) Graduandos em Agronomia, Escola de Agronomia da UFBA.

$\left({ }^{5}\right)$ Embrapa Mandioca e Fruticultura, Caixa Postal 7, 44380-000 Cruz das Almas (BA). 


\section{INTRODUÇÃO}

A enxertia é uma técnica utilizada na horticultura com o objetivo de controlar os patógenos de solo, induzir o florescimento, a tolerância ao encharcamento, alcalinidade e salinidade do solo, aumentando a produção e a qualidade dos frutos (YAMAKAWA, 1982; CAÑIZARES E Goto, 1998; Blanco, 1999; Kobori, 1999; Peil, 2003). Como alternativa de controle de patógenos radiculares, a enxertia em solanáceas (tomate, berinjela e pimentão) e cucurbitáceas (pepino, melão e melancia) tem sido bastante utilizada (KAWAIDE, 1985; Gómez, 1997). Apesar de ser muito utilizada na produção comercial de mudas de hortaliças em países como Japão, Holanda e Espanha, é uma técnica de uso recente no Brasil (PEIL, 2003). Mudanças positivas e/ou negativas podem ocorrer nas plantas enxertadas e, de acordo com LeE (1994), as características de frutos como forma, cor e textura da casca ou da polpa e teor de sólidos solúveis podem ser influenciados pelo porta-enxerto.

A qualidade do fruto refere-se ao conjunto de atributos físicos, sensoriais e a sua composição química. Nas hortaliças, esses atributos, notadamente cor, aroma, sabor e textura devem ser considerados em conjunto, pois são pouco representativos da qualidade, se considerados isoladamente. Essas informações são importantes não apenas para satisfazer as exigências do consumidor, mas também, por possibilitar a seleção genética de novas cultivares, seleção de práticas otimizadas de produção e de práticas adequadas ao manuseio pós-colheita (Chitarra e Chitarra, 1990).

No fruto maduro do tomate, a composição química é determinada na matéria sólida, que representa ao redor de $5 \%$ da polpa do fruto. No entanto, aproximadamente $92 \%$ dessa matéria seca é formada por vários compostos carbônicos, metade dos quais se constitui de açúcar como a glicose e frutose e um oitavo refere-se aos outros ácidos orgânicos que, conjuntamente com os açúcares, contribuem com o típico sabor ácido/doce (Morgan, 2001). Segundo KADER et al. (1978), considera-se o fruto do tomateiro saboroso quando a relação sólidos solúveis totais / acidez total titulável (SST/ATT) é superior a 10 e de alta qualidade quando os valores são superiores a $0,32 \%$ e 3\%, respectivamente, para acidez titulável e sólidos solúveis totais. YAMAKAWA (1982) relata que o híbrido KNVF e outros híbridos recomendados como porta-enxertos para tomateiro são muito vigorosos, podendo causar produção excessiva de folhas, o que muitas vezes resulta em frutos pequenos, mal formados e com maturação desuniforme.
Considerando a importância do controle preventivo de doenças do solo e a exigência do mercado consumidor por frutos com melhor sabor, há necessidade de se avaliar o comportamento das combinações de plantas a serem enxertadas, principalmente no que se refere à qualidade do fruto. Levando em consideração esses argumentos, este trabalho teve como objetivo a caracterização física e físico-química de frutos de tomateiro oriundos de plantas enxertadas em comparação com plantas pés-franco.

\section{MATERIAL E MÉTODOS}

O experimento foi instalado no viveiro do Departamento de Fitotecnia da Escola de Agronomia da Universidade Federal da Bahia (UFBA), na Fazenda Santo Agostinho (área de pequeno produtor hortícola), localizada no município de Cruz das Almas (BA). As análises foram realizadas no Laboratório de Fisiologia Vegetal e Pós-Colheita da Embrapa Mandioca e Fruticultura, em Cruz das Almas, município localizado a $12^{\circ} 40^{\prime} 19^{\prime \prime}$ de latitude Sul e 3906'22" de longitude Oeste de Greenwich, tendo $220 \mathrm{~m}$ de altitude (Almeida, 1999). O clima é tropical quente e úmido, Aw a Am, segundo a classificação de Köppen. A temperatura média e a umidade média, registradas no período de avaliação (outubro de 2003 a fevereiro de 2004) foram de $24,77^{\circ}$ C e 78,40\% respectivamente.

Como porta-enxerto utilizou-se o híbrido Hawaii 7996, resistente à murcha bacteriana (JAUNET E WAng, 1999), obtido do Centro Asiático de Pesquisa e Desenvolvimento de Hortaliças (Asian Vegetable Research and Development Center-AVRDC) em Taiwan. Como enxerto foram utilizados três materiais comerciais do grupo Santa Cruz: cv. Santa Clara, cv. Santa Cruz Kada e o híbrido Débora Plus, todos suscetíveis a murcha bacteriana causada por Ralstonia solanacearum (SUANE, 2004) e facilmente adquiridos no mercado local e utilizados por pequenos produtores da região.

\subsection{Produção de mudas de tomateiro}

Para a produção das mudas, utilizou-se como substrato uma mistura de Plantmax ${ }^{\circledR}$ e areia lavada, na proporção 2:1 (v:v). As mudas do porta-enxerto (híbrido Hawaii 7996) e os pés-franco foram produzidos em sacos pretos de polietileno $(7,0 \mathrm{~cm} \mathrm{x}$ $18,5 \mathrm{~cm}$ ) com $500 \mathrm{~mL}$ de substrato, com semeadura realizada em outubro de 2003. As mudas dos enxertos 'Santa Clara', 'Santa Cruz Kada' e 'Débora Plus' foram produzidas em copos descartáveis de $300 \mathrm{~mL}$, sendo a semeadura realizada 8 a 10 dias após a do porta-enxerto. 
A enxertia foi realizada com as mudas do porta-enxerto, contendo de cinco a seis folhas verdadeiras e o enxerto com mudas tendo de três a quatro folhas verdadeiras, conforme descrito por YAMAKAWA (1982). Utilizou-se o método de fenda cheia, que consiste em seccionar transversalmente o portaenxerto acima da segunda folha verdadeira, seguida da abertura de uma fenda com profundidade de 1,5 $\mathrm{cm}$ e o enxerto foi seccionado com um corte tipo cunha, acima das folhas cotiledonares. Utilizou-se para união das plantas, fitas do plástico Parafilm $\mathrm{M}^{\circledR}$ (American National Can, Neenah, WI). Após a enxertia, as mudas foram mantidas em câmara úmida dentro de um viveiro com luminosidade de $50 \%$, por 10 dias. No 11. ${ }^{\circ}$ dia, as mudas foram retiradas da câmara úmida e mantidas no viveiro com tela de sombreamento de $50 \%$, para aclimatação.

\subsection{Transplante das mudas de tomateiro para o campo}

Aos 13 dias após a enxertia, foi realizado o transplante das mudas enxertadas e dos pés-franco (com 42 dias após semeadura) para o campo, utilizando-se o espaçamento de $1,0 \mathrm{~m}$ entre fileiras duplas, 0,80 m entre fileiras simples e $0,50 \mathrm{~m}$ entre plantas, com sistema de plantio em quincôncio. A irrigação foi feita por gotejamento duas vezes por dia e as plantas foram conduzidas com uma haste, sendo podadas acima da sexta inflorescência. Realizou-se o raleamento dos frutos deixando apenas seis frutos / inflorescência, para todos os tratamentos.

O delineamento experimental foi em blocos ao acaso, com seis tratamentos (as plantas enxertadas 'Hawaii 7996'-'Santa Clara', 'Hawaii 7996'-'Santa Cruz Kada', 'Hawaii 7996'-'Débora Plus' e os pésfranco 'Santa Clara', 'Santa Cruz Kada' e 'Débora Plus') e cinco repetições de campo, sendo a parcela útil composta por seis plantas. Foram colhidos quatro frutos (em estádio uniforme de maturação, completamente vermelhos) por planta, nas seis plantas da parcela útil.

\subsection{Avaliação física e físico-química dos frutos}

As seguintes características foram avaliadas: massa média do fruto $(\mathrm{g})$; diâmetros transversal e longitudinal (mm), com auxílio de paquímetro digital; $\mathrm{pH}$, pelo método potenciométrico (peagômetro Hanna HI8417); sólidos solúveis totais (SST) expressos em ${ }^{\circ}$ Brix, pelo método refratométrico (PEARSON, 1973); acidez total titulável (ATT) expressa em g $100 \mathrm{~g}^{-1} \mathrm{de}$ ácido cítrico, pelo método acidimétrico (AssOciation OF Official Analytical Chemists, 1980) e a relação SST/ ATT, com quatro repetições analíticas.
Os dados foram submetidos à análise de variância, sendo as médias comparadas pelo teste de Tukey, a 5\% de probabilidade, utilizando-se o programa estatístico SISVAR (FERREIRA, 2000).

\section{RESULTADOS E DISCUSSÃO}

A enxertia não afetou as características físicas dos frutos (Tabela 1). Nas cultivares comerciais Santa Clara (SC) e Santa Cruz Kada (SCK), bem como em suas combinações Hawaii 7996 (HW7996) - SC e HW7996 - SCK, observou-se massa média dos frutos superior às verificadas por MARTINS (1992), nas condições de verão de Jaboticabal (SP), que foi de $53 \mathrm{~g}$ para ambas as cultivares no cultivo em campo. Essas condições favoreceram a ocorrência de doenças fúngicas e bacterianas devido à alta precipitação pluvial, umidade elevada e calor intenso, afetando sobremaneira a massa média dos frutos. Em relação à 'Débora Plus', a massa média do fruto $(86,6 \mathrm{~g})$ foi similar à observada por CARVALHO et al. (2005) para a cultivar Débora Max (90,8 g), em cultivo protegido no outono-inverno de Piracicaba. Esses resultados demonstram que, provavelmente, para os híbridos oriundos do Débora (Plus e Max), a época do ano e o sistema de cultivo não influem na massa média do fruto.

Dentre as características físico-químicas avaliadas, a relação SST/ATT não foi afetada pela enxertia e não variou significativamente entre as cultivares (Tabela 2), cujos valores verificados neste experimento para as cultivares, o híbrido e combinações testadas variaram de 12,60 a 15,40, sendo considerados por KADER et al. (1978) como indicativos de frutos saborosos. Esses valores são maiores que os verificados por CARVALHO et al. (2005) para os híbridos Débora Max (Tipo Santa Cruz), Carmen e Diana (Tipo Salada), em ambiente protegido no outono-inverno. A maior luminosidade, na primavera-verão e no cultivo em céu aberto, estimula a atividade fotossintética da planta e a produção de açúcares, os quais são armazenados nos frutos, explicando assim, o maior valor observado na cultivar Débora Plus, comparada ao Débora Max em ambiente protegido.

$\mathrm{O}$ pH e a acidez são fatores de extrema importância quando se analisa o nível de aceitação de um produto pelo consumidor, pois frutos excessivamente ácidos são rejeitados para o consumo (BorguinI, 2002). Neste trabalho, a enxertia afetou o $\mathrm{pH}$ do fruto do tomateiro e as cultivares Santa Clara e Santa Cruz Kada enxertadas foram mais ácidas que seus respectivos pés-franco. Essa alteração pode ter sido afetada pelo porta-enxerto. 
Apesar de ter havido efeito da enxertia no $\mathrm{pH}$, este não comprometeu a classificação do tomate como fruto ácido que, segundo GIORDANO et al. (2000), deverá ter $\mathrm{pH}$ inferior a 4,5. Entre as combinações testadas, em magnitude 'Hawaii 7996' - 'Débora Plus' foi a menos ácida e não diferiu dos pés-franco das demais cultivares (Tabela 2), sendo, portanto, a combinação que poderá ter maior aceitação pelos consumidores.

Quanto à acidez total titulável (Tabela 2), representada pelo teor de ácido cítrico, os valores variaram de $0,27 \%$ a $0,36 \%$, sem diferença entre as cultivares. No caso do Débora Plus, a ATT foi de $0,36 \%$, sendo semelhante ao de BorguinI (2002), para o híbrido Débora $(0,37 \%)$ em cultivo orgânico. Já em ambiente protegido, Carvalho et al. (2005) constataram, no híbrido Débora Max, acidez total titulável de $0,40 \%$, valor que pode ser considerado similar aos descritos para o Débora Plus.

Nos sólidos solúveis totais ( ${ }^{\circ}$ Brix), estão os principais componentes que dão o sabor ao fruto do tomateiro e que influenciam na escolha do consumidor e no rendimento industrial (GIORDANO et al., 2000; Pierro, 2002). No híbrido Débora Plus, sem diferir de sua combinação (Hawaii 7996 - Débora Plus), observou-se o maior ${ }^{\circ}$ Brix, e na cultivar Santa Cruz Kada e a sua combinação (Hawaii 7996 - Santa Cruz Kada), sem diferir de Santa Clara e sua combinação (Hawaii 7996 - Santa Clara), notaram-se os menores valores (Tabela 2). Para Débora Plus, o valor verificado $(4,95)$ foi semelhante ao obtido por Borguini $(2002)$ para o híbrido Débora, em cultivo orgânico e convencional $(4,9)$.

Tabela 1. Características físicas de frutos de tomate oriundos de plantas enxertadas, Hawaii 7996 (HW7996) como porta-enxerto, com as cultivares comerciais Santa Clara (SC), Santa Cruz Kada (SCK) e o híbrido Débora Plus (DP), e de pés-franco de SC, SCK e DP, Cruz das Almas, 2003/2004

\begin{tabular}{lccc}
\hline Tratamentos & Massa média ${ }^{(1)}$ & $\begin{array}{c}\text { Diâmetro }{ }^{(1)} \\
\text { transversal }\end{array}$ & $\begin{array}{c}\text { Diâmetro } \\
\text { longitudinal }\end{array}$ \\
\hline HW7996 -SC & $\mathrm{g}$ & $55,66 \mathrm{a}$ & $60,46 \mathrm{a}$ \\
HW7996-SCK & $101,27 \mathrm{a}$ & $52,87 \mathrm{a}$ & $57,92 \mathrm{a}$ \\
HW7996-DP & $89,07 \mathrm{a}$ & $50,59 \mathrm{a}$ & $59,31 \mathrm{a}$ \\
'Santa Clara' & $84,00 \mathrm{a}$ & $52,84 \mathrm{a}$ & $57,31 \mathrm{a}$ \\
'Santa Cruz Kada' & $87,80 \mathrm{a}$ & $51,50 \mathrm{a}$ & $56,04 \mathrm{a}$ \\
'Débora Plus' & $86,72 \mathrm{a}$ & $51,39 \mathrm{a}$ & $59,31 \mathrm{a}$ \\
\hline C.V. (\%) & $86,55 \mathrm{a}$ & 4,84 & 4,27 \\
\hline
\end{tabular}

Médias seguidas da mesma letra minúscula nas colunas, não diferem entre si pelo teste de Tukey, a $5 \%$ de probabilidade.

( $\left.{ }^{1}\right)$ Média de quatro repetições analíticas.

Tabela 2. Características físico-químicas de frutos de tomate oriundos de plantas enxertadas, Hawaii 7996 (HW7996) como portaenxerto, com as cultivares comerciais 'Santa Clara' (SC), 'Santa Cruz Kada' (SCK) e o híbrido 'Débora Plus' (DP) e de pésfranco de SC, SCK e DP, Cruz das Almas (BA), 2003/2004

\begin{tabular}{|c|c|c|c|c|}
\hline Tratamentos & $\mathrm{pH}$ & $\operatorname{SST}^{*}(1)$ & ATT $^{*}$ & $\mathrm{SST} / \operatorname{ATT}^{*(1)}$ \\
\hline & & ${ }^{\circ}$ Brix & ${\mathrm{g} 100 \mathrm{~g}^{-1}}^{-1}$ & \\
\hline HW7996 - SC & $4,04 \mathrm{c}$ & $4,30 \mathrm{bc}$ & $0,28 \mathrm{bc}$ & $15,40 \mathrm{a}$ \\
\hline HW7996 - SCK & $4,09 \mathrm{bc}$ & $3,95 \mathrm{c}$ & $0,27 \mathrm{c}$ & 14,66 a \\
\hline HW7996 - DP & $4,30 \mathrm{ab}$ & $4,70 \mathrm{ab}$ & $0,35 \mathrm{ab}$ & $13,29 \mathrm{a}$ \\
\hline 'Santa Clara' & $4,47 \mathrm{a}$ & $4,20 \mathrm{bc}$ & $0,31 \mathrm{abc}$ & $13,68 \mathrm{a}$ \\
\hline 'Santa Cruz Kada' & $4,35 \mathrm{a}$ & $3,95 \mathrm{c}$ & $0,32 \mathrm{abc}$ & $12,60 \mathrm{a}$ \\
\hline 'Débora Plus' & $4,36 \mathrm{a}$ & $4,95 \mathrm{a}$ & $0,36 \mathrm{a}$ & $13,73 \mathrm{a}$ \\
\hline C.V. (\%) & 2,40 & 6,23 & 10,40 & 9,53 \\
\hline
\end{tabular}

(*) Sólidos solúveis totais (SST) e Acidez total titulável (ATT).

Médias seguidas da mesma letra minúscula nas colunas, não diferem entre si pelo teste de Tukey, a $5 \%$ de probabilidade.

Média de quatro repetições analíticas. 
Observou-se, também, que nas características formato e cor não houve diferenças entre frutos oriundos das plantas enxertadas e seus respectivos pés-franco. Notou-se que a enxertia com o híbrido Hawaii 7996 não alterou as características fenotípicas das cultivares comerciais.

Os resultados deste trabalho evidenciam que não houve incompatibilidade entre o híbrido Hawaii 7996 e as cultivares comerciais Santa Clara e Santa Cruz Kada e o híbrido Débora Plus. Devido à enxertia não ter alterado significativamente as características físicas e físico-químicas dos frutos, esse híbrido pode ser utilizado como porta-enxerto, sem prejuízo à qualidade do fruto.

\section{CONCLUSÕES}

1. A enxertia com o híbrido 'Hawaii 7996' como porta-enxerto pode ser usada com as cultivares comerciais Santa Clara e Santa Cruz Kada e o híbrido Débora Plus, sem prejuízo para a qualidade do fruto do tomateiro.

2. No híbrido Débora Plus, observou-se maior teor de sólidos solúveis totais do que nas cultivares.

3. Dentre as combinações, em magnitude 'Hawaii 7996' - 'Débora Plus' produziu frutos com melhores características físico-químicas.

\section{AGRADECIMENTOS}

Ao produtor hortícola Sr. José Augusto Coutinho Cardoso, por ter cedido a área para realização do experimento.

Ao Dr. Jaw-Fen Wanga pelo fornecimento das sementes do híbrido Hawaii 7996 do 'Asian Vegetable Research and Development Center' (AVRDC), de Taiwan.

Ao Sr. Arildo Mariano Rego, da Empresa Seminis (SVS DO BRASIL SEMENTES LTDA), pelo fornecimento de sementes de tomate cv. Santa Clara.

\section{REFERÊNCIAS}

ALMEIDA, O.A. Informações metereológicas do CNP: Mandioca e Fruticultura Tropical. Cruz das Almas, BA: EMBRAPA-CNPMF, 1999. 35p. (EMBRAPA- CNPMF. Documentos, 34)

A.O.A.C. Official methods of analysis. Association of Official Analytical Chemists. 12.ed. Washington, 1980. 1018 p.
BLANCO, F.F. Tolerância do pepino enxertado à salinidade em ambiente protegido e controle da salinização do solo. 1999 . 104 f. Dissertação (Mestrado em Agronomia / Irrigação e Drenagem). Escola Superior de Agricultura Luiz de Queiroz, Universidade de São Paulo, Piracicaba.

BORGUINI, R.G. Tomate (Lycopersicon esculentum Mill.) orgânico: o conteúdo nutricional e opinião do consumidor. 2002. 110 f. Tese (Mestre em Agronomia / Ciência e Tecnologia de Alimentos). Escola Superior de Agricultura Luiz de Queiroz - USP, Piracicaba.

CAÑIZARES, K.A.L.; GOTO, R. Crescimento e produção de pepino em função da enxertia. Horticultura Brasileira, Brasília, v.16, n.2, p.110-113, 1998.

CARDOSO, S.C. Controle da murcha bacteriana do tomateiro com a incorporação de guandu e crotalária ao solo e com enxertia em porta-enxerto resistente. 2004. 72 f. Dissertação (Mestrado em Ciências Agrárias / Fitotecnia) - Escola de Agronomia, Universidade Federal da Bahia, Cruz das Almas.

CARVALHO, L.A.; TESSARIOLI NETO, J.; ARRUDA, M.C.; JACOMINO, A.P.; MELO, P.C.T. Caracterização físico-química de híbridos de tomate de crescimento indeterminado em função do espaçamento e número de ramos por planta. Revista Brasileira de Agrociência, Pelotas, v.11, n.3, p. 295-298, 2005.

CHITARRA, M.I.F.; CHITARRA, A.B. Pós-colheita de frutos e hortaliças: fisiologia e manuseio. 1.ed. Lavras: ESAL/FAEPE, 1990. 320p.

FERREIRA, P.V. Estatística experimental aplicada à agronomia. 3.ed. Maceió: EDFAL, 2000. 422p

GIORDANO, L.B.; SILVA, J.B.C. da; BARBOSA, V. Escolha de cultivares e plantio. In: SILVA, J.B.C. da; GIORDANO, L.B. (Ed.). Tomate para processamento industrial. Brasília: Embrapa Comunicação para Transferência de Tecnologia, 2000. p.36-59.

GÓMEZ, A.M. Injerto de hortalizas. Valência: Generalitat Valenciana, 1997. 88p. (Divulgación técnica, 40)

JAUNET, T.X.; WANG, J.F. Variation in genotype and aggressiveness of Ralstonia solanacearum race 1 isolated from tomato in Taiwan. Phytopathology, v.89, p.320-327, 1999.

KADER, A.A.; MORRIS, L.L.; STEVENS, M.A.; ALBRIGHTHOLTON,M. Composition and flavor quality of fresh market tomatoes as influenced by some postharvest handling procedures. Journal of American Society for Horticulture Science, Alexandria, v.113, n.5, p.742-745, 1978.

KAWAIDE, T. Utilization of roosttocks in cucurbits production in Japan. Japan Agricultural Research Quarterly, Ibaraki, v.18, p.284-289,1985.

KOBORI, R.F. Controle da murcha de Fitóftora (Phytophthora capsici) em pimentão (Capsicum annuum L.) através da enxertia. Botucatu, 1999. 138 f. Tese (Doutorado em Agronomia / Proteção de Plantas) - Faculdade de Ciências Agronômicas, Universidade Estadual Paulista. 
LEE, J.M. Cultivation of grafted vegetables. I. Current status, grafting methods and banefits. Hortscience, Alexandria, v.29, p.235-239, 1994.

MARTINS, G. Uso de casa de vegetação com cobertura plástica na tomaticultura de verão. 1992. 65 f. Tese (Doutorado em Agronomia / Produção Vegetal) - Faculdade de Ciências Agrárias e Veterinárias, Universidade Estadual Paulista, Jaboticabal.

MORGAN, L. Tomato fruit flavor and quality evaluation. Part I. Disponível em: <www.fertcut.com/search.cmf> Acesso em 6 Jan. 2001.
PEARSON, D. Laboratory techniques in food analysis. 1.ed. London: Butterworths, 1973. p.58-60.

PEIL, R.M. A enxertia na produção de mudas de hortaliças. Ciência Rural, Santa Maria, v.33, n.6, p.1169-1177, 2003.

PIERRO, A. Gosto bom. Cultivar-Hortaliças e Frutas, Pelotas, RS, n.14, p.10-12, jun./jul, 2002.

YAMAKAWA, K. Use of rootstocks in Solanaceous fruitvegetable production in Japan. Japan Agricultural Research Quarterly, Ibaraki, v.15, n.3, p. 175-180, 1982. 